\title{
Reappraisal of the role of dolasetron in prevention and treatment of nausea and vomiting associated with surgery or chemotherapy
}

This article was published in the following Dove Press journal:

Cancer Management and Research

23 February 2012

Number of times this article has been viewed

\section{S Michael Roberts \\ Dmitri S Bezinover \\ Piotr K Janicki}

Department of Anesthesiology, Penn State College of Medicine, Penn State Milton S Hershey Medical Center, Hershey, PA, USA
Correspondence: Piotr K Janicki Department of Anesthesiology, Penn State Milton S Hershey Medical Center, 500 University Dr, HI87, PO Box 850,

Hershey, PA I7033-0850, USA

$\mathrm{Tel}+\mathrm{I} 71753 \mid 7021$

Fax + 7175316221

Email pjanicki@hmc.psu.edu

\begin{abstract}
Chemotherapy-induced nausea and vomiting and postoperative nausea and vomiting are one of the most frequent but also very concerning consequences for patients undergoing chemotherapy or surgical procedures under general anesthesia. There are a variety of mechanisms involved in the activation of nausea and vomiting. Serotonin, a ubiquitous central and peripheral neurotransmitter, is thought to be the predominant mediator of the perception of nausea and triggering of the vomiting response in both the brain and the periphery via the 5-hydroxytryptamine type $3\left(5-\mathrm{HT}_{3}\right)$ receptor pathways. 5- $\mathrm{HT}_{3}$ receptor antagonists disrupt this pathway, largely at the level of the vagal afferent pathways, to decrease nausea and vomiting. This review will focus on dolasetron, an older but sill commonly used 5-HT 3 receptor antagonist and its multimodal mechanism of action, safety and tolerability, patient considerations, and a review of the current literature on its use to combat both chemotherapy-induced and postoperative nausea and vomiting in these two important patient populations.
\end{abstract}

Keywords: dolasetron, 5- $\mathrm{HT}_{3}$ antagonists, postoperative, chemotherapy, nausea and vomiting

\section{Background}

Over 1.5 million patients are diagnosed with cancer each year in the United States. ${ }^{1}$ Many of these individuals will undergo chemotherapy for their disease; however, the consequences and side effects of the treatment are feared by many. Of these side effects, chemotherapy-induced nausea and vomiting (CINV) is one of the most concerning adverse effects for patients initiating treatment, even more so than the associated alopecia. ${ }^{2}$ Overall, up to $70 \%-80 \%$ of patients undergoing chemotherapy may experience emesis. ${ }^{3} \mathrm{CINV}$ may be a precipitating factor in patients abandoning therapy, with a potential negative impact on outcomes. ${ }^{4}$ Aside from patient satisfaction, uncontrolled CINV may result in malnutrition, dehydration, weight loss, and electrolyte imbalances, and could lead to several types of complications, such as fractures, esophageal tears, and wound dehiscence. ${ }^{2,3}$ Clearly, reduction of this significant side effect improves quality of life for patients undergoing chemotherapy. The knowledge that their adverse effects can be effectively managed may encourage more individuals to undergo therapy and potentially improve their outcomes dramatically.

Likewise, more than 40 million surgeries are performed per year in the United States. ${ }^{5}$ Of this large number, nearly one-third of patients experience postoperative nausea and vomiting (PONV). ${ }^{6} \mathrm{PONV}$ is one of the most commonly reported adverse effects of anesthesia. Even patients with zero known risk factors carry a $10 \%$ risk of PONV. This risk increases dramatically to $61 \%$ and $79 \%$, respectively, when 3 or 4 risk factors exist (female gender, nonsmoker, history of motion sickness, postoperative 
opioid use, and a history of PONV). Much like CINV, PONV may have significant detrimental effects on surgical outcome, including aspiration, wound dehiscence, and esophageal rupture. ${ }^{7,8}$ PONV prophylaxis is an extremely common perioperative practice, even in patients without risk factors for PONV due to the potential adverse outcomes and increased cost of care when PONV is inadequately controlled. 5-Hydroxytryptamine type $3\left(5-\mathrm{HT}_{3}\right)$ receptor antagonists are generally a mainstay of this practice and are administered many times each day in the operating room.

Serotonin, a ubiquitous central and peripheral neurotransmitter, is thought to be the predominant mediator of the perception of nausea and triggering of the vomiting response in both the brain and the periphery via the $5-\mathrm{HT}_{3}$ receptor pathway. ${ }^{8}$ Though these receptors are present in the area postrema, which is the chemoreceptor trigger zone for vomiting in the brain, the evidence suggests that the predominant site of action for $5-\mathrm{HT}_{3}$ receptor antagonists is in the peripheral vagal afferents (Figure 1). High concentrations of serotonin are found in the enterochromaffin cells of the gut. Toxins, such as chemotherapy, can trigger release of serotonin from these cells, with subsequent activation of $5-\mathrm{HT}_{3}$ receptors in vagal afferent pathways which synapse in the nucleus tractus solitarius in the medulla. This, in turn, activates efferent pathways to cause the act of vomiting. ${ }^{3,8}$ $5-\mathrm{HT}_{3}$ receptor antagonists disrupt this pathway, largely at the afferent vagal level, to decrease nausea and vomiting. ${ }^{3}$ This paper will focus on dolasetron, a commonly used $5-\mathrm{HT}_{3}$ receptor antagonist, and its multimodal mechanism of action, safety and tolerability, patient considerations, and a review of the current literature on its use to combat both CINV and PONV in these two important patient populations.

\section{Pharmacology and pharmacokinetics of dolasetron}

Peripheral serotonin acts on multiple subtypes of 5-HT receptors throughout the peripheral nervous system. The primary serotonin receptor involved in the emesis pathway is the $5-\mathrm{HT}_{3}$ receptor. ${ }^{3}$ The $5-\mathrm{HT}_{3}$ receptor is a ligand-gated ion channel present on the abdominal vagal afferents which, when activated, initiates a cascade of signals throughout the central nervous system to cause the sensation of nausea and the act of vomiting via multiple efferent pathways. ${ }^{3,9}$ Dolasetron mesylate is a pseudopelletierine-derived pure $5-\mathrm{HT}_{3}$ antagonist which acts to suppress the sensation of nausea and the vomiting response. ${ }^{8,9}$ Dolasetron has a short elimination half-life of $0.13-0.24$ hours and is rapidly converted by carbonyl reductase to its active form, hydrodolasetron, which has an approximately 50-fold higher affinity for the $5-\mathrm{HT}_{3}$ receptor. $^{7-9}$ Hydrodolasetron reaches its peak plasma concentration at $0.5-0.6$ hours and has a mean plasma elimination half-life of 4-8 hours when administered intravenously. These characteristics give dolasetron an extended duration of action beyond that of ondasetron, the novel 5- $\mathrm{HT}_{3}$ antagonist. When administered orally, it reaches its peak plasma concentration at one hour and has a plasma elimination half-life of 5-10 hours. Oral bioavailability ranges from $70 \%-89 \%$ depending on increasing age. ${ }^{9}$ Hydrodolasetron is predominantly conjugated with glucuronide and/or sulfate groups, as well as

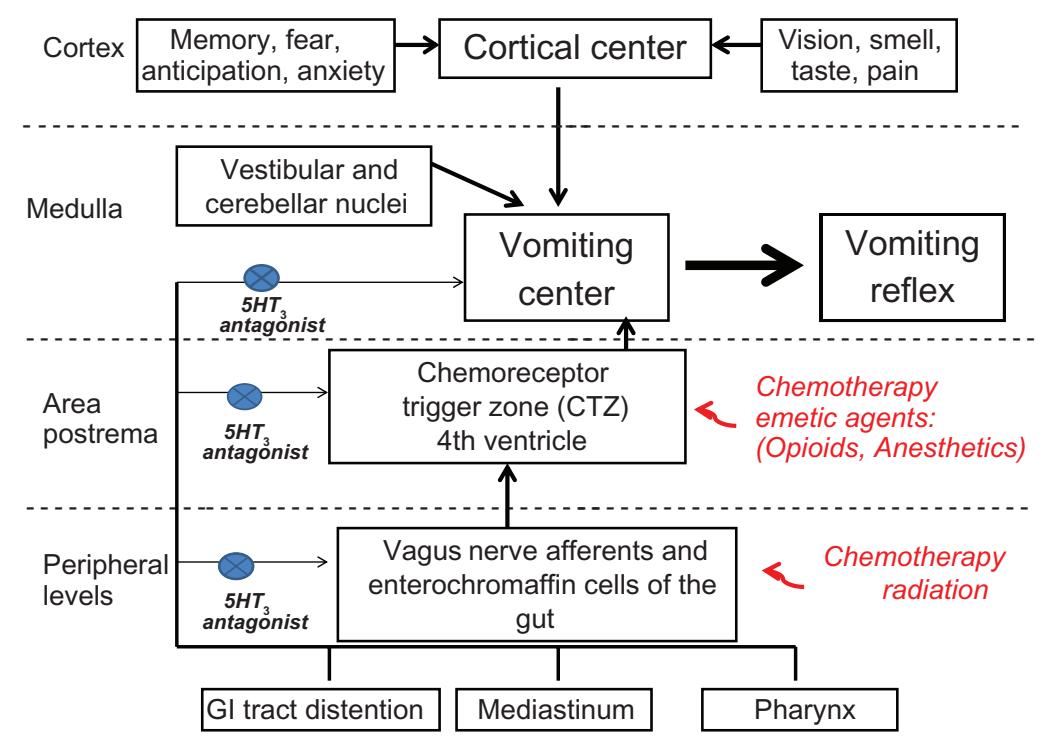

Figure I Schematic representation of the mechanisms of emesis associated with chemotherapy-induced and postoperative nausea and vomiting. 
oxidated with different forms of cytochrome P450 (CYP). The conjugated forms of hydrodolasetron are then excreted $59 \%$ in the urine and $25 \%$ in the feces ${ }^{7,9}$ (Figure 2).

The metabolism of hydrodolasetron and most other $5-\mathrm{HT}_{3}$ receptor antagonists (with the notable exception of granisetron) is, in part, dependent on the CYP2D6 isoform system. Genetic polymorphism in the CYP2D6 isoform system is responsible for alterations in the rates of the metabolism of compounds which are inactivated by this system. This system is responsible for the metabolism of approximately $25 \%$ of all prescribed drugs; therefore, these polymorphisms may have a profound clinical impact in certain circumstances. More than 90 distinct alleles have been identified. Carriers of the polymorphic alleles can be classified, based on the metabolic rate of the reference compounds, as extensive metabolizers (wild-type), poor metabolizers, intermediate metabolizers, or ultrarapid metabolizers. These polymorphisms vary by population. For example, up to $10 \%$ of Caucasians, but less than $2 \%$ of Asians and African-Americans, show the poor metabolizer phenotype. Up to $20 \%$ of certain global populations exhibit the ultrarapid metabolizer phenotype. These variants may impact the efficacy of the drugs they metabolize. ${ }^{7,10}$

Dolasetron, for example, may have increased activity and duration of action in the poor metabolizer population, but may have markedly decreased efficacy in the ultrarapid metabolizer population. These polymorphisms could also impact the adverse effects of dolasetron, because these effects have been directly correlated with serum hydrodolasetron levels. ${ }^{11}$

\section{Safety and tolerability of dolasetron}

Since the development of the $5-\mathrm{HT}_{3}$ receptor antagonists, the overwhelming majority of studies have found them to have a wide margin of safety and to be well tolerated. ${ }^{7}$ In fact, the consensus statement on postoperative nausea and vomiting prophylaxis published in 2003 reported that all $5-\mathrm{HT}_{3}$ receptor antagonists are "equally safe". ${ }^{10}$ The most commonly reported adverse reaction to dolasetron is headache, with an incidence of up to $24 \% .{ }^{9}$ Other commonly reported events are mild, and include diarrhea, fatigue, and dizziness. ${ }^{1,3,7,9}$ However, limited, yet more recently published data suggest there may be evidence of significant cardiovascular events associated with administration of dolasetron.

Early data demonstrated the possibility of prolonged cardiac conduction intervals in both healthy volunteers and perioperative or chemotherapy patients; however, these changes were felt to be transient and not clinically significant. ${ }^{9}$ Trigg and Higa most recently published a review of the CINV literature in 2010 and found no or extraordinarily rare adverse cardiovascular events. ${ }^{1,3}$ However, there exists some limited evidence that even modest doses of dolasetron can be responsible for significant cardiovascular complications.

Dolasetron has been shown to slow cardiac depolarization by blocking fast sodium channels, thereby reducing maximum upstroke velocity of the action potential. ${ }^{12-14}$ This effect causes changes in multiple electrocardiographic parameters, including heart rate, PR interval, QRS duration and, at increased doses (2.4 $\mathrm{mg} / \mathrm{kg})$, the QTc interval. ${ }^{15}$ There is also evidence to suggest that many drugs, including dolasetron, also interact with potassium channels, thereby affecting repolarization. ${ }^{16}$ QTc changes are generally considered to be due to a widened QRS and increases in heart rate; however, there are limited reports of true JT prolongation as well. ${ }^{11,12,17}$ These effects have been noted to be directly correlated with the serum hydrodolasetron concentrations and may persist for up to 24 hours (the noted duration of therapeutic effect of a single dose of dolasetron). ${ }^{11,18,19}$ A thorough examination of the current literature will show that these reports are limited and similar to other drugs of the class.

\section{Patient considerations regarding dolasetron}

Given the aforementioned findings, particular consideration should be given to certain patient populations. Foremost, patients with a pre-existing history of widened QRS or prolonged QTc on electrocardiography should be particularly

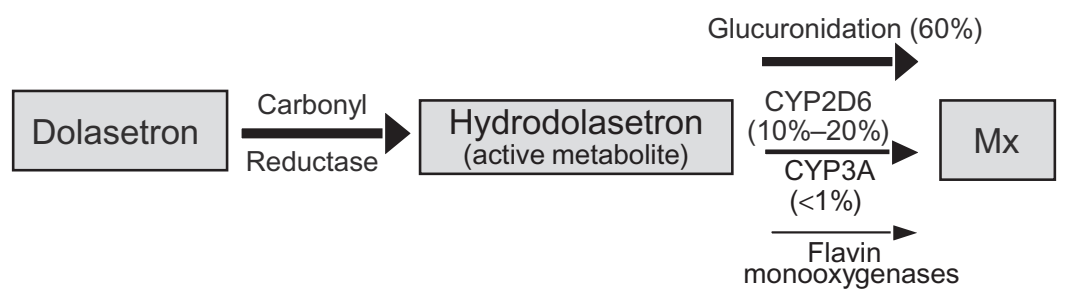

Figure 2 Metabolic pathways of dolasetron.

Abbreviations: CYP2D6, cytochrome P450 2D6 isoform; CYP3A, cytochrome P450 3A isoform; Mx, metabolism. 
concerning, especially at the higher doses required for CINV (1.8-2.4 mg/kg). Up to $10 \%-30 \%$ of asymptomatic individuals may have a prolonged QTc at baseline. ${ }^{20}$ Likewise, administration of dolasetron in patients known to be predisposed to unstable tachyarrhythmias should also be avoided. However, when choosing a replacement antiemetic, it should be noted that ondansetron has also been shown to induce arrhythmia and prolong QTc, though to a lesser extent than dolasetron. ${ }^{12,21-23}$ This is thought to be due to a blockade of potassium channels, which, in turn, prolongs repolarization. ${ }^{11}$ Palonosetron has also been shown to prolong QTc by as much as $3.4 \mathrm{msec}$ at doses as low as $0.25 \mathrm{mg} .{ }^{24}$ Based on this information, these patients would likely benefit from therapy outside the $5-\mathrm{HT}_{3}$ receptor antagonist class.

Genetic variability may also play a role in identifying patients susceptible to significant adverse reactions to dolasetron and other $5-\mathrm{HT}_{3}$ receptor antagonists. As previously mentioned, dolasetron is metabolized by the CYP2D6 pathway, which has been shown to exhibit genetic polymorphisms resulting in significant variability in rate of metabolism of substrates. ${ }^{7}$ Dolasetron, tropisetron, and palonosetron all share this common pathway, so this variability will not only affect their antiemetic properties, but may also exacerbate the adverse effects of these drugs. However, palonosetron is reported to be unaffected by poor or extensive metabolizers. Granisetron, on the other hand, is metabolized independent of the CYP2D6 pathway, so these polymorphisms do not affect its properties. ${ }^{10}$ Recent genetic data has also identified a single nucleotide polymorphism within the NOS1AP gene that may place patients at increased risk for developing prolonged QTc after 5- $\mathrm{HT}_{3}$ receptor antagonist administration. ${ }^{20}$ Further investigation into these polymorphisms may allow clinicians to individualize therapeutic regimens more precisely and to treat their patients more effectively. However, dose adjustments for dolasetron are currently unnecessary based on readily available information (age, renal function, and hepatic function). ${ }^{9}$

\section{Renewed clinical data for dolasetron}

Studies evaluating dose responsiveness have found a plateaued dose-response curve for PONV. A pooled analysis performed by Philip et al in 2000 demonstrated the doseresponse curve plateau well in 1946 postoperative patients. Their results showed that doses greater than $12.5 \mathrm{mg}$ achieved no statistically significant increase in complete response. ${ }^{25}$ However, previous data also clearly demonstrate the emetogenic potential of chemotherapy to be much greater than that of PONV, based on dose requirements. In an early review of dolasetron, Balfour and Goa demonstrated a complete suppression of vomiting in $50 \%-70 \%$ of postoperative gynecology patients to doses as low as 12.5-25 mg. ${ }^{9}$ However, patients receiving highly or moderately emetogenic chemotherapy require doses as high as $1.8 \mathrm{mg} / \mathrm{kg}$ to achieve a complete response (defined as no nausea, emesis, or rescue medication use in the first 24 hours) in $50 \%$ and $60 \%-80 \%$ of cases, respectively. An early study by Grote et al compared oral dolasetron doses of 25, 50, 100 , and $200 \mathrm{mg}$, which demonstrated response rates of $44.7 \%, 71.3 \%, 73.2 \%$, and $82.5 \%$, respectively. ${ }^{26}$ Clearly the plateau effect is far less marked in the setting of moderately emetogenic chemotherapy. ${ }^{27}$ Radiation also appears to have a much higher emetogenic potential, because these patients showed complete response after $40 \mathrm{mg}$ of dolasetron. ${ }^{9}$

Many comparative efficacy studies have been published on $5-\mathrm{HT}_{3}$ receptor antagonists as each new generation of the class was developed. Most comparative investigations were based on ondansetron, the novel $5-\mathrm{HT}_{3}$ receptor antagonist, though there are multiple pharmacologic differences in dolasetron compared with ondansetron. The most clinically notable difference is that the increased elimination half-life of hydrodolasetron, the active metabolite of dolasetron, is 2-3 times greater than for ondasetron. Further, hydrodolasetron has selective affinity for the $5-\mathrm{HT}_{3}$ receptor, whereas ondasetron also shows affinity for $5-\mathrm{HT}_{4}$, $5-\mathrm{HT}_{1 \mathrm{~B}}, 5-\mathrm{HT}_{1 \mathrm{C}}, \alpha_{1}$-adrenergic, and opioid $\mu$ receptors. ${ }^{8}$ This less selective affinity profile of ondansetron may result in an increased number of adverse or unintended drug reactions, though studies fail to demonstrate this effect clearly. Early results showed that $50 \mathrm{mg}$ doses of dolasetron were as effective in preventing PONV as $4 \mathrm{mg}$ of ondasetron, with $71 \%$ and $64 \%$ showing a complete response, respectively. ${ }^{9}$ However, based on the previously discussed more recent results by Philip et al, these higher doses may have been unnecessary to achieve the same results. Overall, multiple studies have at least demonstrated noninferiority of dolasetron compared with ondansetron. ${ }^{28-30}$

Comparative studies have also been completed against granisetron, another selective $5-\mathrm{HT}_{3}$ receptor antagonist. In a small retrospective trial $(n=126)$, Hamadani et $\mathrm{al}^{2}$ evaluated antiemetic treatment failure, as defined by nausea or vomiting, in platinum-based chemotherapy comparing dolasetron with granisetron or ondansetron. All 5- $\mathrm{HT}_{3}$ receptor antagonists were given in conjunction with dexamethasone. In this study, no statistically significant difference in treatment failure was noted, which confirms previously published data demonstrating equivalent efficacy between dolasetron, 
granisetron, and ondansetron. ${ }^{31,32}$ Therefore, the authors have concluded that the choice of antiemetic should be based on drug cost in the setting of both PONV and CINV. ${ }^{2,33}$ Steiner et al also found no clinically or statistically significant difference when granisetron was exchanged for dolasetron in the setting of CINV. This interchange resulted in no difference in patient satisfaction, therapeutic effectiveness, functional status, or nausea severity. However, they did note a substantial cost reduction when using dolasetron. ${ }^{34}$ However, when comparing dolasetron $100 \mathrm{mg}$ orally with granisetron $2 \mathrm{mg}$ orally in moderately or highly emetogenic chemotherapy, Tan et al found contradictory results in 2004. Their open-label study of 26 patients demonstrated a complete response rate of $23.1 \%$ for the dolasetron group, while the granisetron group showed a complete response in $69.2 \%$. When comparing the cost-effectiveness noted by the previous two authors, Tan et al found a seven-fold increase in rescue medication use in the dolasetron group, which would clearly reduce the cost benefit of dolasetron. ${ }^{35}$ However, due to the limited number of patients enrolled in this study and the contradictory results of previously published data, any evidence suggesting the superiority of granisetron over dolasetron is extremely limited.

Most recently, dolasetron has been compared headto-head with palonosetron, the newest drug of the class, approved by the US Food and Drug Administration in 2008. The earliest study comparing dolasetron with palonosetron was completed by Eisenberg et al in 2003 . In this noninferiority study, two doses of palonosetron were compared with dolasetron in 592 patients undergoing moderately emetogenic chemotherapy. At 24 hours after chemotherapy (acute phase CINV), intravenous palonosetron $0.25 \mathrm{mg}$ was found have a higher complete response rate of $63.0 \%$ as compared with intravenous dolasetron $100 \mathrm{mg}$ with a $52.9 \%$ complete response $(P=0.049)$. Likewise, at 24-120 hours following chemotherapy (delayed CINV), palonosetron remained superior to dolasetron at $48.1 \%$ and $36.1 \%$, respectively $(P=0.018) .{ }^{24}$ In a meta-analysis by Botrel et al in 2011, palonosetron was found to be superior to all other $5-\mathrm{HT}_{3}$ receptor antagonists, including dolasetron, in preventing acute-phase and late-phase CINV in moderately or highly emetogenic chemotherapy. ${ }^{4}$ In another large, recent study published in 2011, Schwartzberg et al again compared palonosetron with all other $5-\mathrm{HT}_{3}$ receptor antagonists in CINV, this time in the setting of triple therapy with dexamethasone and a $\mathrm{NK}_{1}$ receptor antagonist. In this retrospective study of 4552 patients, palonosetron showed a $17 \%$ lower risk of uncontrolled CINV during 5 days of highly emetogenic chemotherapy. ${ }^{36}$ Overall, the extremely long elimination half-life of palonosetron ( 40 hours) appears to give it a therapeutic advantage over dolasetron. ${ }^{24}$

A large area of recent interest in the dolasetron literature is its safety profile. As previously discussed, dolasetron has been shown to slow cardiac depolarization by blocking fast sodium channels, thereby reducing the maximum upstroke velocity of the action potential. ${ }^{12}$ This action potential effect causes changes in multiple electrocardiographic parameters, including heart rate, PR interval, QRS duration, and, at increased doses $(2.4 \mathrm{mg} / \mathrm{kg})$, the QTc interval. Until recently, these effects were thought to be limited and not clinically significant, with the exception of patients particularly susceptible to these changes (including prolonged QTc at baseline, tachycardia in the setting of acute myocardial infarction). ${ }^{11}$ Case reports have been published describing markedly adverse cardiovascular events resulting from both standard doses of dolasetron and intentional overdose. Rochford et al described the dramatic result of a patient ingesting $2000 \mathrm{mg}$ of dolasetron during an intentional overdose. She became markedly hemodynamically unstable, requiring vasopressors, and her electrocardiogram showed sinus rhythm with first-degree atrioventricular block, nonspecific intraventricular conduction delay, and a markedly prolonged QTc of $611 \mathrm{msec} .^{37}$ This is obviously an extreme example of the adverse cardiovascular effects of dolasetron, but further significant events have been documented.

Higgins and Bunker have described an episode of intraoperative supraventricular tachycardia immediately following the administration of dolasetron $12.5 \mathrm{mg}$, a well established acceptable dose for PONV prophylaxis. An otherwise healthy 45-year-old female became hemodynamically unstable requiring treatment with amiodarone. Her symptoms resolved and, interestingly, her postoperative electrocardiogram showed no signs of prolonged intervals. ${ }^{38}$ Turner et al have also described an episode of acute QTc prolongation with progression to torsades de pointes and ultimately ventricular fibrillation one hour after dolasetron administration..$^{39}$ Clearly, prolongation of QTc has been clearly associated with the development of torsades de pointes and potentially fatal arrhythmia, though only in $1 \%$ of these patients overall. ${ }^{40-42}$

Though these are profound examples of the cardiovascular effects of dolasetron, multiple studies consistently support cardiac conduction changes caused by dolasetron, though the clinical relevance of these changes is controversial. However, in 2010, the Food and Drug Administration issued a drug safety communication stating that dolasetron should no 
longer be administered intravenously for the prevention of CINV. The basis of this statement is the compelling finding of a dose-dependent prolongation in QT, PR, and QRS intervals in recent studies and a report of a nearly three-fold increase in ventricular arrhythmia in patients treated with dolasetron, compared with ondansetron or granisetron, in one study. ${ }^{43,44}$ This, in conjunction with previously documented findings, implies that dolasetron may be proarrhythmic because it prolongs the mean QT/QTc interval by $>20 \mathrm{msec}^{45}$ These findings are only applicable to intravenous dolasetron used at the higher doses necessary for CINV, not the decreased dose needed for PONV prophylaxis. However, the Food and Drug Administration issued a similar warning in September 2011 regarding ondansetron for patients with congenital long QT syndrome, which may further the evidence to suggest that this effect is not unique to dolasetron. ${ }^{46}$

\section{Conclusion}

Dolasetron represents an older type of $5 \mathrm{HT}_{3}$ receptor antagonist. Despite the fact that it has been present on the market for more than 20 years, it is still commonly used for prophylaxis and treatment of both PONV and CINV. Its effectiveness in the treatment of PONV and CINV is similar to other $5-\mathrm{HT}_{3}$-antagonists, including ondansetron, topisetron, and granisetron, but it seems to be inferior when compared with newer, longer-acting $5-\mathrm{HT}_{3}$-antagonists like palonosetron. The most commonly reported adverse reaction to dolasetron is headache, which is reported in up to $24 \%$ of patients. Other commonly reported events are mild, and include diarrhea, fatigue, and dizziness. The newer data provide evidence of significant cardiovascular events, in the form of QTc interval prolongation and subsequent arrhythmia associated with dolasetron administration, particularly in the higher dose ranges. In 2010, the Food and Drug Administration issued a drug safety communication stating that dolasetron should no longer be administered intravenously at higher doses for the prevention of CINV, though similar warnings now exist for ondansetron and granisetron for certain susceptible patient populations. Significant prolongation of the QTc interval seems to be common to all 5- $\mathrm{HT}_{3}$ antagonists (with the possible exception of palonosetron) and may represent a class effect for this group of drugs. ${ }^{4}$ Given the aforementioned findings, particular consideration should be given to certain patient populations prior to the administration of $5-\mathrm{HT}_{3}$ receptor antagonists. Foremost, patients with a pre-existing history of widened QRS or prolonged QTc on electrocardiogram should be particularly concerning, especially at the higher doses required for CINV.

\section{Disclosure}

The authors report no conflicts of interest in this work.

\section{References}

1. Trigg ME, Higa GM. Chemotherapy-induced nausea and vomiting: antiemetic trials that impacted clinical practice. J Oncol Pharm Pract. 2010;16:233-244.

2. Hamadani M, Chaudhary L, Awan FT, et al. Management of platinumbased chemotherapy-induced acute nausea and vomiting: is there a superior serotonin receptor antagonist? J Oncol Pharm Pract. 2007;13: 69-75.

3. Navari RM. Pharmacological management of chemotherapy-induced nausea and vomiting. Drugs. 2009;69:515-533.

4. Botrel TEA, Clark OAC, Clark L, et al. Efficacy of palonosetron (pal) compared to other serotonin inhibitors $\left(5-\mathrm{HT}_{3} \mathrm{R}\right)$ in preventing chemotherapy-induced nausea and vomiting $(\mathrm{CINV})$ in patients receiving moderately or highly emetogenic (MoHE) treatment: systematic review and meta-analysis. Support Care Cancer. 2011;19:823-832.

5. Anesthesia Quality Institute. Anesthesia in the United States 2009. Available from: www.aqihq.org. Accessed February 10, 2012.

6. Gan TJ, Meyer T, Apfel CC, et al. Consensus guidelines for managing postoperative nausea and vomiting. Anesth Analg. 2003;97:62-71.

7. Janicki, PK. Cytochrome P4502D6 metabolism and 5-hydroxytryptamine type 3 receptor antagonists for postoperative nausea and vomiting. Med Sci Monit. 2005;11:RA322-238.

8. Gregory RE, Ettinger DS. 5-HT3 receptor antagonists for the prevention of chemotherapy-induced nausea and vomiting. Drugs. 1998;55: 173-189.

9. Balfour JA, Goa KL. Dolasetron: a review of its pharmacology and therapeutic potential in the management of nausea and vomiting induced by chemotherapy, radiotherapy or surgery. Drugs. 1997;54:273-298.

10. Aapro M, Blower P. 5-hydroxytryptamine type-3 receptor antagonists for chemotherapy-induced and radiotherapy-induced nausea and emesis. Cancer. 2005; 104:1-13.

11. Miller DR. Arrhythmogenic potential of antiemetics: perspectives on risk-benefits. Can J Anesth. 2003;50:215-220.

12. Benedict CR, Arbogast R, Martin L, et al. Single-blind study of the effects of intravenous dolasetron mesylate versus ondansetron on electrocardiographic parameters in normal volunteers. J Cardiovasc Pharmacol. 2006;28:53-59.

13. Kuryshev YA, Brown AM, Wang L, et al. Interactions of the 5-hydroxytryptamine 3 antagonist class of antiemetic drugs with human cardiac ion channels. J Pharmacol Exp Ther. 2000;295:614-620.

14. Keefe DL. The cardiotoxic potential of the 5-HT(3) receptor antagonist antiemetics: is there cause for concern? Oncologist. 2002;7:65-72.

15. Baltzer L, Kris MG, Hinkley L, et al. Reversible electrocardio-graphic interval prolongations following the specific serotonin antagonists ondansetron (OND) and dolasetron mesylate (DM): a possible drug class effect without sequelae? Proc Am Soc Clin Oncol. 1994; 13:433a.

16. Cubeddu LX. Iatrogenic CT abnormalities and fatal arrhythmias: mechanisms and clinical significance. Curr Cardiol Rev. 2009;5: 166-176.

17. Hunt TL, Cramer M, Shah A, et al. A double-blind, placebo-controlled, dose-ranging safety evaluation of single-dose intravenous dolasetron in healthy male volunteers. J Clin Pharmacol. 1995;35:705-712.

18. Kantor G. Arrhythmia risk of antiemetic agents. Anesthesiology. 2002;97:286.

19. Keller GA, Ponte ML, Di Girolamo G. Other drugs acting on nervous system associated with QT-interval prolongation. Curr Drug Saf. 2010;5:105-111.

20. Quraishi SA, Schuler GH, Janicki PK. 5HT(3)-receptor antagonists and cardiac repolarization time in patients expressing a novel genetic target associated with baseline QTc interval abnormalities. J Clin Anesth. 2011;23:297-302. 
21. Charbit B, Albaladejo P, Funck-Brentano C, et al. Prolongation of QTc interval after postoperative nausea and vomiting treatment by droperidol or ondansetron. Anesthesiology. 2005;102:1094-1100.

22. Kasinath NS, Malak O, Tetzlaff J. Atrial fibrillation after ondansetron for the prevention and treatment of postoperative nausea and vomiting: a case report. Can J Anaesth. 2003;50:229-231.

23. Hesketh P, Navari R, Grote $T$, et al. Double-bind, randomized comparison of the antiemetic efficacy of intravenous dolasetron mesylate and intravenous ondansetron in the prevention of acute cisplatin-induced emesis in patients with cancer. J Clin Oncol. 1996;14:2242-2249.

24. Eisenberg P, Figueroa-Vadillo J, Zamora R, et al. Improved prevention of moderately emetogenic chemotherapy-induced nausea and vomiting with palonosetron, a pharmacologically novel 5- $\mathrm{HT}_{3}$ receptor antagonist. Cancer. 2003;98:2473-2482.

25. Philip BK, McLeskey CH, Chelly JE, et al. Pooled analysis of three large clinical trials to determine the optimal dose of dolasetron mesylate needed to prevent postoperative nausea and vomiting. The dolasetron prophylaxis study group. J Clin Anesth. 2000;12:1-8.

26. Grote TH, Pineda LF, Figlin RA, et al. Oral dolasetron mesylate in patients receiving moderately emetogenic platinum-containing chemotherapy. Oral Dolasetron Dose Response Study Group. Cancer J Sci Am. 1997;3:45-51.

27. Rubenstein EB, Gralla RJ, Hainsworth JD, et al. Randomized, double blind, dose-response trial across four oral doses of dolasetron for the prevention of acute emesis after moderately emetogenic chemotherapy. Oral Dolasetron Dose-Response Study Group. Cancer. 1997;79: 1216-1224.

28. Mandanas RA, Beveridge R, Rifkin RM, et al. A randomized, multicenter, open-label comparison of the antiemetic efficacy of dolasetron versus ondansetron for the prevention of nausea and vomiting during high-dose myeloablative chemotherapy. Support Cancer Ther. 2005;2: 114-121.

29. Lofters WS, Pater JL, Zee B, et al. Phase III double-blind comparison of dolasetron mesylate and ondansetron and an evaluation of the additive role of dexamethasone in the prevention of acute and delayed nausea and vomiting due to moderately emetogenic chemotherapy. J Clin Oncol. 1997;15:2966-2973.

30. Pater JL, Lofters WS, Zee B, et al. The role of the 5-HT3 antagonists ondansetron and dolasetron in the control of delayed onset nausea and vomiting in patients receiving moderately emetogenic chemotherapy. Ann Oncol. 1997;8:181-185.

31. Audhuy B, Cappelaere P, Martin M, et al. A double-blind, randomized comparison of the anti-emetic efficacy of two intravenous doses of dolasetron mesilate and granisetron in patients receiving high dose cisplatin chemotherapy. Eur J Cancer. 1996;32A:807-813.

32. Roila F, Ballatori E, Tonato $\mathrm{M}$, et al. 5-HT3 receptor antagonists: differences and similarities. Eur J Cancer. 1997;33:1364-1370.
33. Birmingham SD, Mecklenburg BW, Lujan E, et al. Dolasetron versus ondansetron as single-agent prophylaxis for patients at increased risk for postoperative nausea and vomiting: a prospective, double-blind, randomized trial. Mil Med. 2006;171:913-916.

34. Steiner M, Yorgason RZ, Vermeulen LC, et al. Patient outcomes after therapeutic interchange of dolasetron for granisetron. Am J Health Syst Pharm. 2003;60:1023-1028.

35. Tan M, Xu R, Seth R, et al. Granisetron vs dolasetron for acute chemotherapy-induced nausea and vomiting (CINV) in high and moderately high emetogenic chemotherapy: an open-label pilot study. Curr Med Res Opin. 2004;20:879-882.

36. Schwartzberg L, Jackson J, Jain G, et al. Impact of 5-HT3RA selection within triple antiemetic regimens on uncontrolled highly emetogenic chemotherapy-induced nausea/vomiting. Expert Rev Pharmacoecon Outcomes Res. 2011;11:481-488.

37. Rochford M, Kiernan TJ, Aziz A. Dolasetron overdose resulting in prolonged QTc interval and severe hypotension: a case report and literature review. Emerg Med J. 2007;24:515-517.

38. Higgins DJ, Bunker NJ. Dolasetron and peri-operative cardiac arrhythmia. Anaesthesia. 2005;60:936-937.

39. Turner S, Mathews L, Pandharipande P, et al. Dolasetron-induced torsades de pointes. J Clin Anesth. 2007;19:622-625.

40. Roden DM. Drug induced prolongation of the QT interval. $N$ Engl J Med. 2004;350:1013-1022.

41. Algra A, Tijssen JG, Roelandt JR, et al. QT prolongation measured by standard 12-lead electrocardiography is an independent risk factor for sudden death due to cardiac arrest. Circulation. 1991;83:1888-1894.

42. Goodin S, Cunningham R. 5-HT -receptor antagonists for the treatment of nausea and vomiting: a reappraisal of their side-effect profile. Oncologist. 2002;7:424-436.

43. Food and Drug Administration. FDA drug safety communication: Abnormal heart rhythms associated with use of Anzemet (dolasetron mesylate). Available from: http://www.fda.gov/Drugs/DrugSafety/ ucm237081.htm. Accessed November 10, 2011.

44. Schnell FM, Coop AJ. An evaluation of potential signals for ventricular arrhythmia and cardiac arrest with dolasetron, ondansetron, and granisetron in the FDA combined spontaneous reporting system/adverse event reporting system. Curr Ther Res Clin Exp. 2005;66:409-419.

45. Food and Drug Administration. Guidance for Industry E14 clinical evaluation of QT/QTc interval prolongation and proarrhythmic potential for non-antiarrhythmic drugs. Rockville, MD: US Department of Health and Human Services, Food and Drug Administration, Center for Drug Evaluation and Research: Center for Biologics Evaluation and Research, 2005.

46. Blum K. Is QT prolongation a valid reason to abandon Zofran? Anesth News. 2011;37:158.
Cancer Management and Research

\section{Publish your work in this journal}

Cancer Management and Research is an international, peer-reviewed open access journal focusing on cancer research and the optimal use of preventative and integrated treatment interventions to achieve improved outcomes, enhanced survival and quality of life for the cancer patient The journal welcomes original research, clinical \& epidemiological

\section{Dovepress}

studies, reviews \& evaluations, guidelines, expert opinion \& commentary, case reports \& extended reports. The manuscript management system is completely online and includes a very quick and fair peerreview system, which is all easy to use. Visit http://www.dovepress.com/ testimonials.php to read real quotes from published authors. 